\title{
Nucleic Acids - Genes, Drugs, Molecular Lego and More
}

\author{
Robert Häner*
}

\author{
Dedicated to Prof. Dr. Daniel Belluš on the occasion of his $70^{\text {th }}$ birthday
}

\begin{abstract}
Chemically modified nucleic acids find widespread use as tools in research, as diagnostic reagents and even as pharmaceutical compounds. On the background of antisense research and development, the synthesis and evaluation of modified oligonucleotides was intensively pursued in the early to mid nineties in corporate research of former Ciba. Most of these efforts concentrated on the development of sugar and/or backbonemodified derivatives for pharmaceutical applications. Additionally, oligonucleotide metal conjugates were investigated with the goal to develop artificial ribonucleases. Since the turn of the millennium also the potential of non-nucleosidic and non-hydrogen bonding building blocks has increasingly been recognized. Such derivatives possess unique properties that may have an impact in the fields of materials and genetic research. In this brief account, we take a personal look back on some past as well as some recent results.
\end{abstract}

Keywords: Antisense · DNA · Oligonucleotides · siRNA · Supramolecular chemistry

\section{Introduction}

Modified oligonucleotides enjoy widespread interest as molecular probes for diagnostic applications, as versatile tools in basic and applied research, ${ }^{[1,2]}$ and as magic bullets for therapeutic intervention in biological processes. ${ }^{[3]}$ In addition, they are increasingly used as units for the generation of distinct molecular architectures. ${ }^{[4]}$ The well-defined structural features of nucleic acids and related types of oligomers render them valuable building blocks for the generation of nanometer-sized structures. ${ }^{[5]}$ In addition, the combination of the natural nucleotides with novel, synthetic building blocks leads to a further increase in the number of possible constructs and applications. ${ }^{[6]}$ In the following, we will highlight a few examples of our recent findings.

\section{Oligonucleotides Interfering with Gene Expression}

The discovery that short oligonucleotides can specifically inhibit cellular gene expression $^{[7]}$ triggered a decade of intensive research aimed at the design and synthesis of many different types of oligonucleotides (for reviews see e.g. refs. [8-10]). An oligonucleotide can bind to a complementary cellular messenger RNA. Binding is highly specific and follows the WatsonCrick base-pairing scheme. By binding to its target, the oligonucleotide prevents the translation of the messenger RNA into the encoded protein by the ribosomes. Due to the existence of cellular nucleases, however, oligodeoxynucleotides are rapidly degraded in a biological environment and, therefore, of limited use. Chemical modification leads to resistance towards nucleolytic degradation and, hence, increased biological activity of antisense compounds. Besides inferring stability against nucle- ases, the chemical modification should possess a number of other features, such as good hybridization properties, good synthetic accessibility, cellular uptake and induction of RNase H. ${ }^{[11]}$ A few selected examples of modifications resulting from the Central Research Laboratories of former Ciba are shown in Fig. 1.

The objective of developing oligonucleotides into a new class of pharmaceutical compounds has resulted in the introduction of Vitravene ${ }^{\mathrm{TM}}$ as the first antisense compound on the market in 1999 (Fig. 1). This 21mer phosphorothioate oligonucleotide was developed by ISIS Pharmaceuticals for the local treatment of cytomegalovirus induced retinitis. ${ }^{[15,16]}$

\section{Artificial Nucleases}

The properties of oligonucleotides can be altered by covalently attaching lipophilic or polar moieties, different types of peptides,
${ }^{\star}$ Correspondence: Prof. Dr. R. Häner Department of Chemistry and Biochemistry University of Bern

Freiestrasse 3

$\mathrm{CH}-3012$ Bern

Tel: +41316314382

E-Mail: robert.haener@ioc.unibe.ch
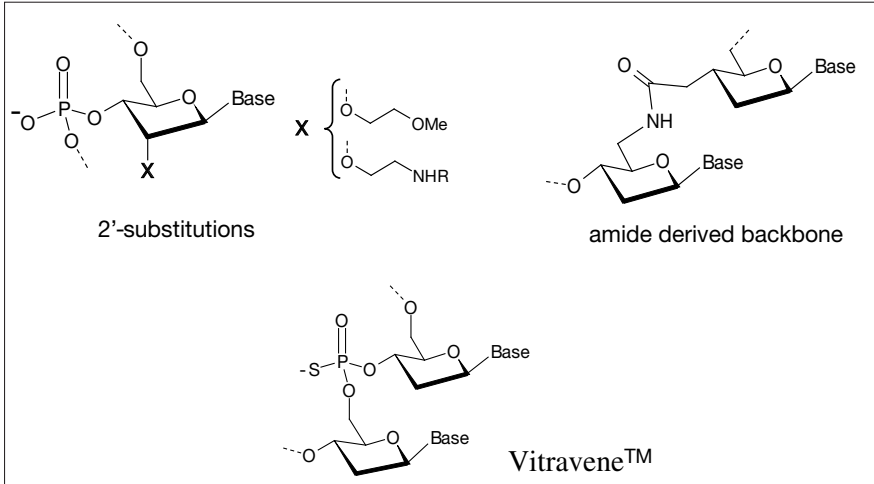

(PS) 5'-GCGTTTGCTCTTCTTCTTGCG
Fig. 1. Selected types of chemically modified oligonucleotides. Top, left: modifications of the ribose; ${ }^{[12,13]}$ right: example of an amidemodified backbone; ${ }^{[14]}$ bottom: Vitravene ${ }^{\mathrm{TM}}$ for the local treatment of cytomegalovirus induced retinitis. 


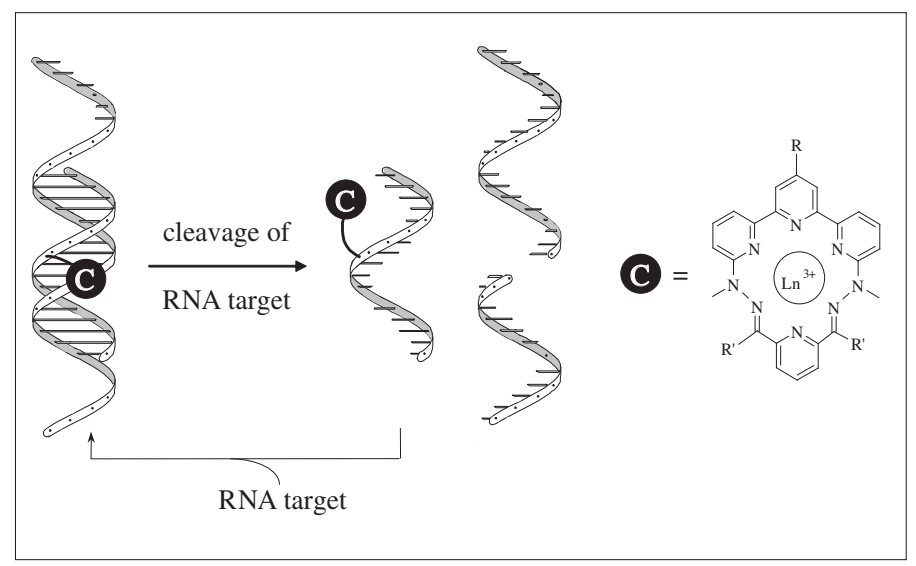

Scheme 1. Illustration of an artificial ribonuclease composed of an oligonucleotide and an attached macrocyclic lanthanide-complex. After binding to its complementary RNA target, strand scission is effected by transesterification of the RNA phosphodiester backbone. Cleavage in the middle of the target was shown to work with multiple turnover.

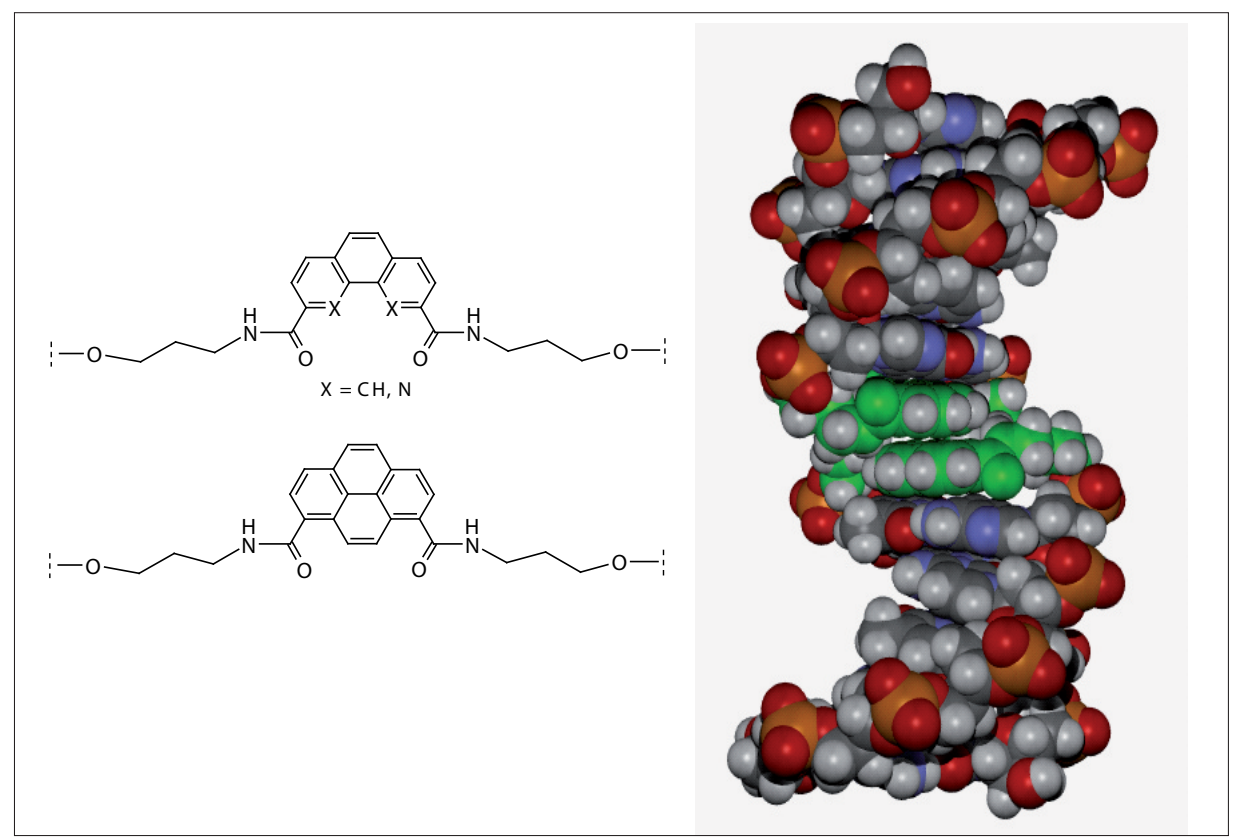

Fig. 2. Model of a DNA duplex containing interstrand stacked pyrene building blocks (green). Different types of non-nucleosidic building blocks used for DNA modification are shown on the left.

enzymes, dyes or intercalators. ${ }^{[17,18]}$ In particular, reactive groups have been linked to oligonucleotides to cleave nucleic acids in a sequence-specific way. Such conjugates have been described as artificial nucleases and find applications as rare cutters of large genomic DNAs ${ }^{[19]}$ or as tools for structural mapping of nucleic acids. In addition, they also have a potential as drugs aimed at destroying DNA and RNA targets. ${ }^{[20]}$ Cleavage of DNA targets may involve oxidative damage and breakage of the DNA backbone. RNA cleavage, on the other hand, usually follows a hydrolytic pathway since RNA is intrinsically more susceptible towards phosphodiester hydrolysis than DNA. This is due to the presence of the 2'-hydroxyl group in RNA, which acts as an internal nucleophile in the transesterification reaction. The synthesis of artificial ribonucleases was also investigated in the Central Research Laboratories and resulted in the development of lanthanide-oligonucleotide conjugates that were shown to cleave large mRNAs in a highly specific way. ${ }^{[21]}$ Furthermore, a special approach involving the hydrolysis of bulged RNA residues led to artificial ribonucleases acting with multiple turnover (illustrated in Scheme 1). ${ }^{[22]}$

\section{DNA Analogues Containing Non- nucleosidic Building Blocks}

During our efforts aimed at the development of DNA mimics containing polyaromatic building blocks with nonnucleosidic linkers, we found that compounds such as phenanthrene, phenanthroline or pyrene give rise to stable hybrids, in which the modified building blocks interact via interstrand stacking. ${ }^{[23,24]}$ In a way, these building blocks serve as surrogates of the natural base pairs. Replacement of the natural base pairs by this kind of building blocks is well tolerated having little influence on hybrid stability compared to an unmodified duplex. ${ }^{[25]}$ Of all modifications, pyrene is most interesting due to its unique spectroscopic properties. Hybridisationinduced excimer formation by pyrenes is highly efficient. ${ }^{[26-30]}$ Due to the large bathochromic shift of the excimer fluorescence $(100 \mathrm{~nm})$ compared to the emission of the monomer, such systems are of interest for applications in materials research as well as in gene-based diagnostics. Since the absorption spectrum of pyrene overlaps only partly with the absorption of the natural bases the structural features of the pyrenes are observable in certain spectral regions. Within the set of building blocks that we have studied (phenanthrene, ${ }^{[23,25]}$ phenanthroline ${ }^{[31,32]}$ and pyrene ${ }^{[32,33]}$ ) the pyrene molecule is an ideal candidate for the assembly of molecular $\pi$-stacks of polyaromatic compounds in a DNA framework. Temperature-dependent UV and fluorescence experiments provided information on the stacking properties of pyrene building blocks, allowing us to draw conclusions on the hybridization process of the DNA mimics. ${ }^{[34]}$ Based on these data, a model of interstrand stacked polyaromatic building blocks was derived (Fig. 2). As expected, interstrand stacking leads to excimer formation of pyrenes that are placed in opposite positions. ${ }^{[35,36]}$

A detailed investigation of pyrenemodified hybrids using CD spectroscopy revealed that extended stretches of pyrenes self-assemble and form helical segments (Fig. 3). ${ }^{[37]}$ The helical structure of the oligopyrene regions was shown to be an intrinsic property of the pyrenes and was largely independent from the sequence of the flanking DNA. ${ }^{[38]}$

Also triple-stranded nucleic acids can serve as architectural motifs to control interactions of non-nucleosidic residues. Thus, we have found that excimer formation can be achieved by proper placement of pyrenes in mono- and di-molecular triple helices. ${ }^{[39]}$ Most notably, the formation of a hitherto unobserved pyrene-phenanthrene exciplex was demonstrated in a triple helical construct. ${ }^{[40]}$ In a particular application, excimer formation was also shown to be useful for the highly specific detection of homopurine target sequences (illustrated in Fig. 4). ${ }^{[41]}$

\section{Conclusions}

Broad-based efforts in the synthesis and evaluation of chemically modified nucleic acids have led to significant achievements in oligonucleotide-mediated interference with gene expression as well as in the development of artificial ribonucleases. Additionally, novel types of non-nucleosidic, 


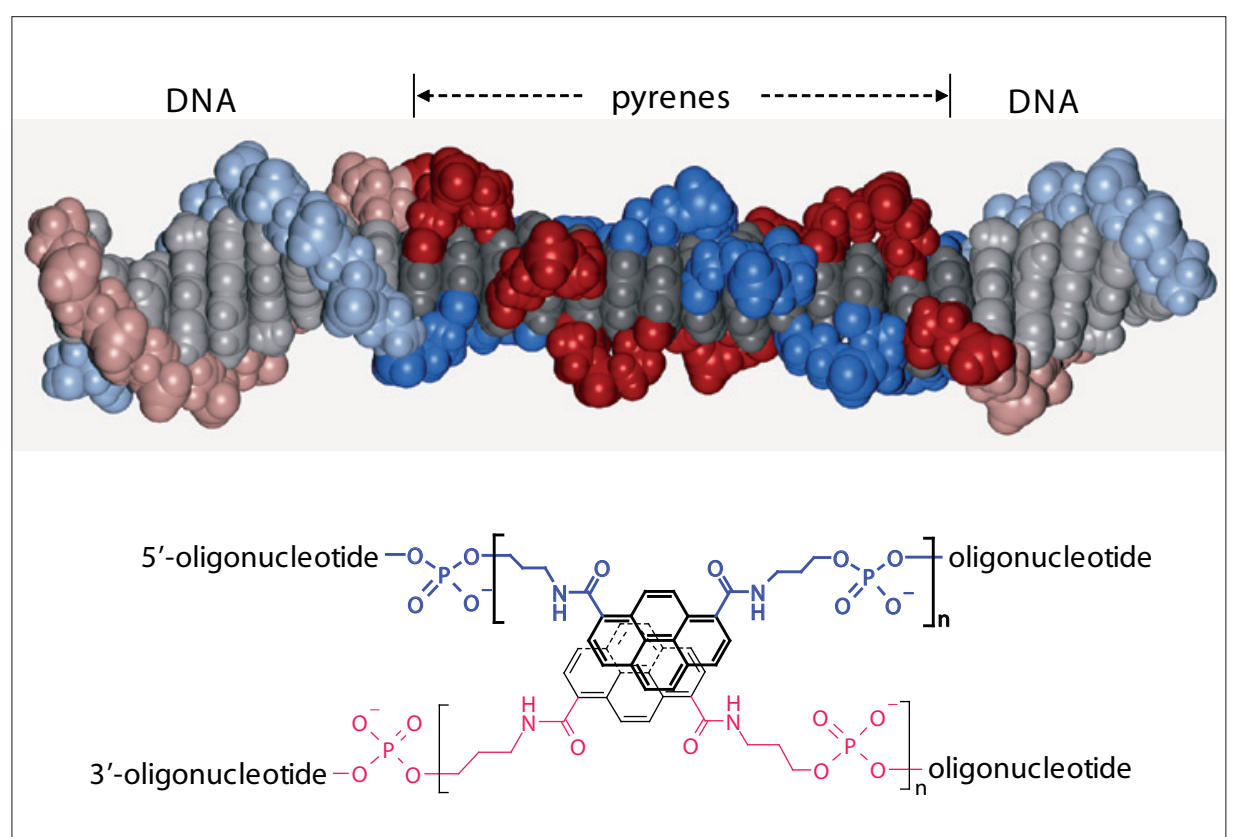

Fig. 3. Model of a helical oligopyrene section embedded into a DNA double helix; pyrene building blocks are shown in grey, linking units in red and blue.

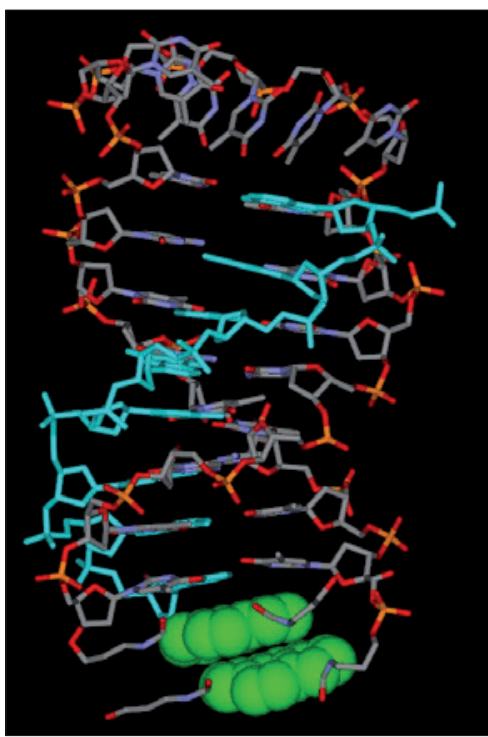

non-hydrogen bonding building blocks are increasingly becoming an important aspect in nucleic acids research. Such building blocks, which are readily incorporated into oligonucleotides, can be regarded as surrogates for the natural base pairs. They allow the formation of stable hybrids, which is supported by interstrand stacking interactions between the aromatic moieties. Due to their special spectroscopic properties, pyrene derivatives appear most interesting for applications in the areas of diagnostics as well as materials research.

\section{Acknowledgements}

Some of the results described herein were accomplished by colleagues at the Central Research Laboratories of former Ciba during the first half of the 1990s. I thank all those colleagues for an exciting time full of enthusiastic

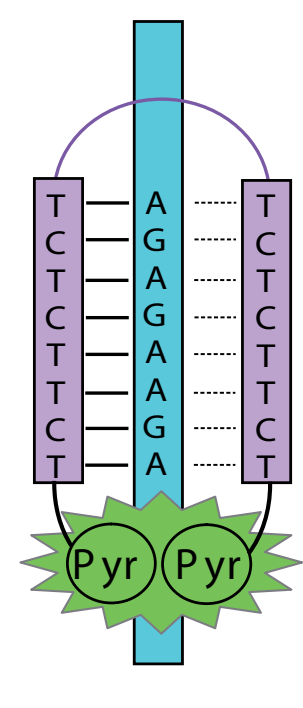

Fig. 4. Illustration of a triplex forming molecular beacon. Binding of the probe to its target sequence is easily detected by excimer formation of the two terminally attached pyrenes.

[7] M. L. Stephenson, P. C. Zamecnik, Proc. Natl. Acad. Sci. USA 1978, 75, 285.

[8] E. Uhlmann, A. Peymann, Chem. Rev 1990, 90, 543.

[9] S. T. Crooke, Antisense Nucleic Acid Drug Dev. 1998, 8,115 .

[10] G. J. Hannon, Nature 2002, 418, 244

[11] W. F. Lima, S. T. Crooke, J. Biol. Chem. 1997, $272,27513$.

[12] P. Martin, Helv. Chim. Acta 1996, 79, 1930.

[13] B. Cuenoud, F. Casset, D. Huesken, F. Natt, R. M. Wolf, K. H. Altmann, P. Martin, H. E. Moser, Angew. Chem. Int. Ed. 1998, 37, 1288.

[14] V. Fritsch, A. De Mesmaeker, A. Waldner, J. Lebreton, M. J. Blommers, R. M. Wolf, Bioorg. Med. Chem. 1995, 3, 321.

[15] K. P. Anderson, M. C. Fox, V. Brown-Driver, M. J. Martin, R. F. Azad, Antimicrob. Agents Chemother. 1996, 40, 2004.

[16] M. D. de Smet, C. J. Meenken, G. J. van den Horn, Ocul. Immunol. Inflamm. 1999, 7, 189.

[17] S. L. Beaucage, R. Iyer, Tetrahedron 1993, 49, 1925

[18] J. Goodchild, Bioconjug. Chem. 1990, 1, 165.

[19] Y. Yamamoto, A. Uehara, A. Watanabe, H. Aburatani, M. Komiyama, Chembiochem 2006 7,673 .

[20] R. Häner, J. Hall, Antisense Nucleic Acid Drug Dev. 1997, 7, 423.

[21] L. Canaple, D. Hüsken, J. Hall, R. Häner, Bioconjug. Chem. 2002, 13, 945.

[22] R. Häner, J. Hall, A. Pfuetzer, D. Huesken, Pure Appl. Chem. 1998, 70, 111.

[23] S. M. Langenegger, R. Häner, Helv. Chim. Acta 2002, 85,3414

[24] S. M. Langenegger, G. Bianké, R. Tona, R. Häner, Chimia 2005, 59, 794 .

[25] S. M. Langenegger, R. Häner, ChemBioChem 2005, 6, 2149 .

[26] K. Yamana, Y. Fukunaga, Y. Ohtani, S. Sato, M. Nakamura, W. J. Kim, T. Akaike, A. Maruyama, Chem. Commun. 2005, 2509.

[27] F. D. Lewis, Y. F. Zhang, R. L. Letsinger, J. Am. Chem. Soc. 1997, 119, 5451.

[28] A. Okamoto, Y. Ochi, I. Saito, Chem. Commun. $2005,1128$.

[29] P. J. Hrdlicka, T. S. Kumar, J. Wengel, Chem. Commun. 2005, 4279.

[30] C. Wagner, M. Rist, E. Mayer-Enthart, H. A. Wagenknecht, Org. Biomol. Chem. 2005, 3, 2062.

[31] S. M. Langenegger, R. Häner, Tetrahedron Lett. 2004, 45, 9273 .

[32] S. M. Langenegger, R. Häner, ChemBioChem 2005, 6, 848 .

[33] H. Bittermann, D. Siegemund, V. L. Malinovskii, R. Häner, J. Am. Chem Soc. 2008, 130, 15285.

[34] F. Samain, V. L. Malinovskii, S. M. Langenegger, R. Häner, Bioorg. Med. Chem. 2008, 16, 27.

列 bers of my research group at the University of Bern for their valuable contributions. Financial support of our research in this area by the Swiss National Foundation is gratefully acknowledged. My sincere thanks go to Daniel Belluš for his tireless efforts for the benefit of basic and applied research in the Swiss chemical industry.

Received: December 18, 2009

[1] S. Verma, S. Jager, O. Thum, M. Famulok, Chem. Record 2003, 3, 51.

[2] O. Kohler, D. V. Jarikote, I. Singh, V. S. Parmar, E. Weinhold, O. Seitz, Pure Appl. Chem. 2005, 77,327

[3] A. De Mesmaeker, R. Häner, P. Martin, H. E. Moser, Acc. Chem. Res. 1995, 28, 366.

[4] N. C. Seeman, Mol. Biotechnol. 2007, 37, 246.

[5] U. Feldkamp, C. M. Niemeyer, Angew. Chem. Int. Ed. 2006, 45, 1856

[6] A. Eschenmoser, Chimia 2005, 59, 836.
[35] S. M. Langenegger, R. Häner, Chem. Commun. 2004, 2792.

[36] S. M. Langenegger, R. Häner, Bioorg. Med. Chem. Lett. 2006, 16, 5062.

[37] V. L. Malinovskii, F. Samain, R. Häner, Angew. Chem. Int. Ed. 2007, 46, 4464.

[38] R. Häner, F. Samain, V. L. Malinovskii, Chem. Eur. J. 2009, 15, 5701.

[39] I. Trkulja, R. Häner, J. Am. Chem. Soc. 2007, $129,7982$.

[40] I. Trkulja, R. Häner, Bioconjug. Chem. 2007, $18,289$.

[41] I. Trkulja, S. M. Biner, S. M. Langenegger, R. Häner, ChemBioChem 2007, 8, 25. 